\title{
Down Regulation of Asparagine Synthetase and 3-Phosphoglycerate Dehydrogenase, and the Up-Regulation of Serine Dehydratase in Rat Liver from Intake of Excess Amount of Leucine Are Not Related to Leucine-Caused Amino Acid Imbalance
}

\author{
Ryoji Yoshimura ${ }^{1}$, Marie TAKAI ${ }^{1}$, Hiroya NAMAKI ${ }^{1}$, Kimiko MinAmI ${ }^{1}$, Wataru IMAmurA ${ }^{2}$, \\ Hisanori $\mathrm{KATO}^{2}$, Yasutomi KAMEI $^{1}$ and Ryuhei KANAMOTO ${ }^{3, *}$ \\ ${ }^{1}$ Laboratory of Molecular Nutrition, Graduate School of Life and Environmental Sciences, \\ Kyoto Prefectural University, Shimogamo, Sakyo-ku, Kyoto 606-8522, Japan \\ ${ }^{2}$ Corporate Sponsored Research Program "Food for Life," Organization for Interdisciplinary Research \\ Projects, The University of Tokyo, Yayoi, Bunkyo-ku, Tokyo 113-8657, Japan \\ ${ }^{3}$ Division of Food Science and Biotechnology, Graduate School of Agriculture, Kyoto University, \\ Gokasho, Uji, Kyoto 611-0011, Japan \\ (Received April 23, 2015)
}

\begin{abstract}
Summary Asparagine synthetase (ASNS), 3-phosphoglycerate dehydrogenase (PHGDH) and serine dehydratase (SDS) in rat liver are expressed in response to protein and amino acid intake. In the present study, we examined the expression of these enzymes in relation to amino acid imbalance caused by leucine. Rats were subjected to leucine administration in the diet or orally between meals. Consumption of more than $2 \%$ leucine in a $6 \%$ casein diet suppressed food intake and caused growth retardation in a dose-dependent manner, but this was not seen in a $12 \%$ or $40 \%$ casein diet. ASNS and PHGDH expression in the liver was significantly induced by the $6 \%$ casein diet and was suppressed by leucine in a dose-dependent manner, whereas the SDS expression was induced. These effects were leucine specific and not seen with ingestion of isoleucine or valine. However, leucine orally administered between meals did not change the food intake or growth of rats fed a $6 \%$ casein die, though it similarly affected the expression of ASNS, PHGDH and SDS in the liver. These results suggest that the growth retardation caused by leucine imbalance was mainly because of the suppression of food intake, and demonstrated that there are no causal relationships between ASNS, PHGDH and SDS expression and amino acid imbalance caused by leucine.
\end{abstract}

Key Words excess leucine, asparagine synthetase, 3-phosphoglycerate dehydrogenase, serine dehydratase, amino acid imbalance

In the present study, we examined whether an excess amount of leucine altered the expression of asparagine synthetase (ASNS, EC 6.3.1.1), 3-phosphoglycerate dehydrogenase (PHGDH, EC 1.1.1.95) and serine dehydratase (SDS, EC 4.2.1.13) in the liver of rats maintained on a low-protein diet and caused amino acid imbalance.

It is well known that leucine is not only a component amino acid of proteins, but also a signaling molecule, promoting protein synthesis and inhibiting protein degradation (1-4). Because of these roles, leucine is used as a supplement to activate muscle protein synthesis. Although the supplemental intake of amino acids is considered to be safe, the intake of indispensable amino acids such as leucine or methionine causes anorexia, growth retardation and a fatty liver under low-protein dietary conditions in animal experiments (5-7). These phenomena are called amino acid "imbalance," i.e., supplementation of a single indispensable amino acid decreases the nutritive value of a low-protein diet rather than increases it $(8,9)$. Although there have been many

*To whom correspondence should be addressed.

E-mail: kanamoto@kais.kyoto-u.ac.jp reports concerning amino acid imbalance, the mechanism causing it is not yet clear.

Recently, using an animal model, we assessed the safe level of leucine intake from the viewpoint of gene expression (10). The results demonstrated that the tolerable upper intake level of supplemental leucine is $2 \%$ of the diet of rats maintained on $6 \%$ casein as the sole protein source. Supplementation of leucine at over $2 \%$ of the diet reduced food intake and body weight gain. The pathway analysis after the cDNA microarray analysis of the rat liver showed that leucine most significantly affected the metabolism of alanine and aspartate, in addition to the metabolism of glycine, serine and threonine.

It has been reported that ASNS and PHGDH are markedly induced in the liver of rodents that are fed a low-protein diet $(11,12)$.

The mammalian ASNS is the only enzyme that catalyzes asparagine synthesis and converts L-aspartate and L-glutamine to L-asparagine and L-glutamate, respectively, in an ATP-dependent manner $(13,14)$. The required amount of asparagine is usually sufficiently provided by biosynthesis; hence, asparagine is consid- 
ered to be a dispensable amino acid. However, weaned rats that were fed an asparagine-deprived diet showed growth retardation. This growth retardation recovered within several days after asparagine deprivation, probably because of the induction of ASNS in the liver (15). It has also been reported that when cells lacking a functional ASNS are exposed to asparaginase (EC 3.5.1.1), they undergo cell cycle arrest in G1, and in some cases such as acute lymphatic leukemia (ALL), die by apoptosis (16). Thus, asparaginase has been used as a therapeutic drug against ALL (17). These studies indicate that de novo synthesis of asparagine by ASNS is essential for survival when the availability of asparagine is insufficient to fulfill cellular metabolic demands.

Although there are two ways to synthesize serinethe phosphorylation pathway and the combined action of the glycine cleavage system and serine hydroxymethyltransferase - it is primarily synthesized by the phosphorylation pathway. In the first step of the phosphorylation pathway, 3-phosphoglycerate derived from glycolysis is metabolized into phosphohydroxypyruvate by $\mathrm{PHGDH}$, a rate-limiting enzyme. Yoshida et al. have successfully generated PHGDH-knockout mice and demonstrated that systemic PHGDH-knockout embryos die 13.5 d post coitum (18), whereas brain-specific $\mathrm{PHGDH}-$ knockout mice are viable despite microcephaly (19). These results clearly showed that the serine provided from the mother did not satisfy their requirement and the fetus needs the de novo synthesis of most of the serine for tissue growth and development. Recently, significant upregulation of PHGDH expression was observed in proliferating, differentiating and neoplastic tissues $(20,21)$. Thus, these results suggest that the expression of PHGDH is critical for serine de novo synthesis to fulfill the cellular requirement of serine for growth and differentiation.

In contrast to a low-protein diet, a high-protein diet induces SDS. SDS is expressed specifically in the liver and kidneys, and catalyzes serine and threonine to produce pyruvate and $\alpha$-ketobutyrate, respectively. It has been reported that SDS in the liver plays an important role in serine catabolism and contributes to $90 \%$ of serine degradation (22). Comparing growing rats with mature rats, we have demonstrated that SDS expression in the liver is induced by protein intake beyond their protein requirement $(23,24)$. It thus shows that the induction of SDS is closely related to protein nutrition. Our study has also revealed that SDS is strongly induced by the intake of leucine, compared to that of other branchedchain amino acids (BCAAs) (25), suggesting that leucine contributes to the regulation of SDS expression.

Marked induction of ASNS and PHGDH in the liver by a low-protein diet and of SDS by a high-protein diet is considered to be a very important adaptive mechanism to abnormal protein nutrition. If leucine disturbs the expression of these genes, it may affect the growth of animals. For this reason, we examined ASNS, PHGDH and SDS expression in relation to leucine-induced amino acid imbalance.

\section{MATERIALS AND METHODS}

Animals care. Male Sprague-Dawley rats (10 wk old) were purchased from Japan SLC, Inc. (Hamamatsu, Japan). They were housed individually in stainless-steel cages in an air-conditioned room at $23 \pm 1^{\circ} \mathrm{C}$ with a 12 -h light/dark cycle (lights on from 08:00 to 20:00). Rats were acclimated for 3 or $4 \mathrm{~d}$ and provided ad libitum access to water and a $20 \%$ casein diet based on AIN93G (10). Then, the rats were assigned to the experimental groups described below. Food intake and body weight were measured daily. Growth rate was calculated by dividing initial body weight into final body weight of the experiment. The range of the initial body weight was 280-320 g. All experimental methods were approved by the Animal Experiment Committee of Kyoto Prefectural University and The University of Tokyo. All the rats were managed in line with the "Guidelines for Care and Use of Laboratory Animals".

Experimental design. In this study, we used 10-wkold rats in which the protein requirements are fulfilled by ingestion of a 10-12\% casein $\operatorname{diet}(23,24)$.

Experiment 1: Rats $(n=72)$ were divided into 12 groups and fed a diet containing 6\% (low), 12\% (normal) or $40 \%$ (high) casein supplemented with $0,2,4$ or $8 \%$ leucine (kindly provided by Ajinomoto, Co., Inc., Kawasaki, Japan) for $1 \mathrm{wk}$. The composition of the experimental diets is described elsewhere (10). The rats were allowed free access to food and water during the experimental period.

Experiment 2: Rats $(n=72)$ were fed a 6,12 or $40 \%$ casein diet for $1 \mathrm{wk}$. Food was given ad libitum from 20:00 to 08:00 and water was available at all times. Each casein diet group was separated into four groups and orally administrated leucine at $0,0.13,0.25$ or $0.50 \mathrm{~g} / \mathrm{mL} / 100 \mathrm{~g}$ body weight, at 11:00 daily. The amounts of administrated leucine corresponded to a 0 , $2,4,8 \%$ leucine diet based on the assumption that the average intake of diet was $6 \mathrm{~g} / 100 \mathrm{~g}$ body weight/d. The appropriate amount of leucine was suspended in $0.5 \%$ xanthane gum (San-Ei Gen F.F.I Inc., Osaka, Japan) in phosphate-buffered saline (PBS).

Experiment 3: To examine the specificity of leucine, rats $(n=20)$ were divided into four groups and fed a $6 \%$ casein diet, a $6 \%$ casein diet containing $8 \%$ leucine, or a $6 \%$ casein diet containing $8 \%$ isoleucine or $7.2 \%$ valine (equal to $8 \%$ leucine on a nitrogen basis). Food and water were available at all times.

Sample preparation. On the final day, the diet was removed at 08:00. The rats were anesthetized by intraperitoneal administration of sodium pentobarbital ( $50 \mathrm{mg} / \mathrm{kg}$ body weight) and killed by exsanguination with transection of the inferior vena cava in a randomized order at 12:00. The livers were excised, rinsed with ice-cold PBS, frozen in liquid nitrogen and stored at $-30^{\circ} \mathrm{C}$.

Quantitative RT-PCR. Total RNA from the liver was isolated by the acid guanidinium isothiocyanate-phenol-chloroform method as described elsewhere (26). Total RNA (10 ng) was used for the reverse transcription 
reaction using the PrimeScript ${ }^{\mathrm{TM}} \mathrm{RT}$ reagent Kit (Takara Bio Inc., Otsu, Japan), according to the manufacturer's protocol. Quantitative PCR was performed using SYBR Premix Taq $^{\mathrm{TM}}$ II (Takara Bio Inc.) with Rotor-Gene $\mathrm{Q}$ (Qiagen, Hilden, Germany). The expression levels of Asns, Phgdh, Sds and $\beta$-actin were measured individually. To normalize, the relative expression level of Asns, Phgdh and Sds was obtained by dividing their expression levels by the expression level of $\beta$-actin, which is a housekeeping gene. Primers used for cDNA amplification: Asns (forward 5'-ACTGCTGTTTTGGCTTC-3' and reverse 5'-TCTCACCGTCCACATTG-3'); Phgdh (forward 5'-TCTGAAGAATGCTGGGACCT-3' and reverse 5'-GCTTAGCGTTCACCAAGTTCA-3'); Sds (forward 5'-TCACCAGTGTTGCCAAGG-3' and reverse 5'-TCGTCTACGAACTTCTCG-3'); $\beta$-actin (forward 5'-CTACAATGAGCTGCGTGTGG-3' and reverse 5'-ATGGCTACGTACATGGCTGG-3'). Pre-incubation was performed at $94^{\circ} \mathrm{C}$ (Phgdh) or at $95^{\circ} \mathrm{C}$ (Asns, Sds and $\beta$-actin). The thermal cycling conditions for Asns, Phgdh, Sds and $\beta$-actin are summarized in Table 1.

Western blotting. Liver $(300 \mathrm{mg})$ was homogenized in a buffer comprising $0.1 \mathrm{M}$ potassium hydrogen phosphate, $0.1 \mathrm{M}$ potassium dihydrogenphosphate, $\mathrm{pH} 8.0$, $1 \mathrm{~mm}$ EDTA, $0.1 \mathrm{~mm}$ [(4-formyl-5-hydroxy-6-methylpyridin-3-yl) methoxy] phosphonic acid, $1 \mathrm{~mm}(2 S, 3 S)$ 1,4-bis (sulfanyl) butane-2,3-diol and $0.5 \mathrm{~mm}$ phenylmethanesulfonyl fluoride using a Polytron homogenizer. Insoluble material was removed by centrifugation for $30 \mathrm{~min}$ at $4^{\circ} \mathrm{C}$ and $10,000 \times g$, and the supernatant was centrifuged for $60 \mathrm{~min}$ at $4^{\circ} \mathrm{C}$ and $100,000 \times g$. The protein concentration was measured using the Lowry method. Equal amounts of protein were separated by SDS-PAGE and transferred to PVDF membranes (Merck Millipore, Darmstadt, Germany). The membranes were blocked with 5\% skim milk in PBS containing 0.1\% Tween 20 (blocking buffer) for $1 \mathrm{~h}$ at room temperature.

Table 1. Thermal cycling parameters for primer optimization. The thermal cycling conditions for Asns, Phgdh, Sds and $\beta$-actin.

\begin{tabular}{lccc}
\hline \multirow{2}{*}{ Gene } & Temperature $\left({ }^{\circ} \mathrm{C}\right)$ & Time $(\mathrm{s})$ & \# of cycles \\
\hline \multirow{2}{*}{ Asns } & 95 & 10 & 50 \\
& 58 & 30 & \\
& 72 & 45 & \\
\hline \multirow{2}{*}{ Phgdh } & 95 & 4 & 45 \\
& 60 & 20 & \\
& 72 & 30 & \\
\multirow{2}{*}{ Sds } & 95 & 5 & 45 \\
& 53 & 30 & \\
\hline \multirow{2}{*}{$\beta$-Actin } & 72 & 30 & \\
& 94 & 4 & \\
& 62 & 20 & \\
\hline
\end{tabular}

Table 2. Food intake and growth rate of rats fed a 6, 12 or $40 \%$ casein diet containing $0,2,4$ or $8 \%$ leucine.

\begin{tabular}{|c|c|c|c|c|c|}
\hline \multirow{2}{*}{$\begin{array}{c}\text { Casein } \\
(\%)\end{array}$} & \multirow{2}{*}{$\begin{array}{l}\text { Leucine } \\
\qquad(\%)\end{array}$} & \multirow{2}{*}{$\begin{array}{c}\text { Food intake } \\
\text { (g/100 g B.W./d) }\end{array}$} & \multicolumn{2}{|c|}{ Body weight $^{1}$} & \multirow{2}{*}{$\begin{array}{l}\text { Growth rate } \\
\text { (Fold) }\end{array}$} \\
\hline & & & $\begin{array}{l}\text { Beginning } \\
(\mathrm{g})\end{array}$ & $\begin{array}{l}\text { End } \\
\text { (g) }\end{array}$ & \\
\hline \multirow[t]{4}{*}{6} & 0 & $6.3 \pm 0.4^{\mathrm{ab}}$ & $326.6 \pm 8.1$ & $352.1 \pm 12.6$ & $1.08 \pm 0.02^{\mathrm{a}}$ \\
\hline & 2 & $6.3 \pm 0.8^{\mathrm{a}}$ & $318.4 \pm 13.0$ & $343.1 \pm 25.2$ & $1.08 \pm 0.04^{\mathrm{a}}$ \\
\hline & 4 & $5.1 \pm 0.5^{\mathrm{c}}$ & $325.7 \pm 10.5$ & $326.7 \pm 10.2$ & $1.00 \pm 0.04^{\mathrm{b}}$ \\
\hline & 8 & $2.9 \pm 1.0^{\mathrm{d}}$ & $327.0 \pm 15.6$ & $290.9 \pm 18.5$ & $0.89 \pm 0.04^{c}$ \\
\hline \multirow[t]{4}{*}{12} & 0 & $5.2 \pm 0.6^{\mathrm{bc}}$ & $326.3 \pm 7.8$ & $345.2 \pm 8.2$ & $1.06 \pm 0.03^{\mathrm{ab}}$ \\
\hline & 2 & $5.7 \pm 0.2^{\mathrm{abc}}$ & $325.5 \pm 15.1$ & $355.0 \pm 16.3$ & $1.09 \pm 0.02^{\mathrm{a}}$ \\
\hline & 4 & $5.6 \pm 0.5^{\mathrm{abc}}$ & $326.0 \pm 7.5$ & $360.2 \pm 10.7$ & $1.11 \pm 0.04^{\mathrm{a}}$ \\
\hline & 8 & $5.3 \pm 0.8^{\mathrm{abc}}$ & $321.7 \pm 6.1$ & $347.8 \pm 7.3$ & $1.08 \pm 0.03^{\mathrm{a}}$ \\
\hline \multirow[t]{4}{*}{40} & 0 & $5.2 \pm 0.4^{\mathrm{abc}}$ & $327.5 \pm 6.7$ & $358.4 \pm 3.4$ & $1.09 \pm 0.01^{\mathrm{a}}$ \\
\hline & 2 & $5.2 \pm 0.5^{b c}$ & $319.2 \pm 10.9$ & $345.7 \pm 13.7$ & $1.08 \pm 0.03^{\mathrm{a}}$ \\
\hline & 4 & $5.3 \pm 0.3^{\mathrm{abc}}$ & $322.5 \pm 10.1$ & $345.4 \pm 11.8$ & $1.07 \pm 0.02^{\mathrm{a}}$ \\
\hline & 8 & $5.1 \pm 0.2^{\mathrm{c}}$ & $326.5 \pm 13.7$ & $352.0 \pm 20.7$ & $1.08 \pm 0.02^{\mathrm{a}}$ \\
\hline \multicolumn{6}{|c|}{ Statistical significance } \\
\hline \multicolumn{2}{|c|}{ Casein } & NS & & & $p<0.001$ \\
\hline \multicolumn{2}{|c|}{ Leucine } & $p<0.001$ & & & $p<0.001$ \\
\hline \multicolumn{2}{|c|}{ Casein $\times$ Leucine } & $p<0.001$ & & & $p<0.001$ \\
\hline
\end{tabular}

Values are mean \pm SD. $n=6$. Data were tested by two-way ANOVA, to analyze the casein and leucine effect. When a significant interaction was detected, Tukey-Kramer tests for multiple comparisons were performed to determine significance of differences among individual groups. Labeled values in the same column without a common letter are statistically different, $p<0.05$.

${ }^{1}$ Original data used were the same as in Fig. 1 cited in reference (10), and were recalculated to evaluate the effect of casein and leucine on growth of rats by two-way ANOVA. 
Table 3. Food intake and growth rate of rats fed a 6,12 or $40 \%$ casein diet and subjected to oral administration of leucine.

\begin{tabular}{|c|c|c|c|c|c|}
\hline \multirow{2}{*}{$\begin{array}{c}\text { Casein } \\
(\%)\end{array}$} & \multirow{2}{*}{$\begin{array}{c}\text { Leucine } \\
\text { (g/100 g B.W.) }\end{array}$} & \multirow{2}{*}{$\begin{array}{c}\text { Food intake } \\
\text { (g/100 g B.W./d) }\end{array}$} & \multicolumn{2}{|c|}{ Body weight } & \multirow{2}{*}{$\begin{array}{l}\text { Growth rate } \\
\qquad \text { (Fold) }\end{array}$} \\
\hline & & & $\begin{array}{l}\text { Beginning } \\
(\mathrm{g})\end{array}$ & $\begin{array}{l}\text { End } \\
(\mathrm{g})\end{array}$ & \\
\hline \multirow[t]{4}{*}{6} & 0.00 & $5.1 \pm 0.3^{\mathrm{ab}}$ & $322.6 \pm 11.3$ & $338.1 \pm 18.1$ & $1.03 \pm 0.02^{\mathrm{ab}}$ \\
\hline & 0.13 & $5.9 \pm 0.3^{\mathrm{a}}$ & $322.8 \pm 6.9$ & $341.3 \pm 15.0$ & $1.05 \pm 0.03^{\mathrm{ab}}$ \\
\hline & 0.25 & $5.7 \pm 0.3^{\mathrm{ab}}$ & $319.4 \pm 4.0$ & $329.7 \pm 10.8$ & $1.03 \pm 0.02^{\mathrm{ab}}$ \\
\hline & 0.50 & $5.0 \pm 0.6^{\mathrm{ab}}$ & $322.1 \pm 9.3$ & $321.6 \pm 12.3$ & $0.99 \pm 0.03^{b}$ \\
\hline \multirow[t]{4}{*}{12} & 0.00 & $4.8 \pm 0.3^{\mathrm{b}}$ & $318.1 \pm 6.9$ & $333.2 \pm 5.9$ & $1.04 \pm 0.03^{\mathrm{ab}}$ \\
\hline & 0.13 & $5.0 \pm 0.8^{\mathrm{ab}}$ & $320.5 \pm 8.1$ & $330.7 \pm 24.0$ & $1.03 \pm 0.06^{\mathrm{ab}}$ \\
\hline & 0.25 & $5.1 \pm 0.6^{\mathrm{ab}}$ & $315.0 \pm 14.8$ & $322.8 \pm 23.6$ & $1.02 \pm 0.03^{\mathrm{ab}}$ \\
\hline & 0.50 & $5.6 \pm 0.4^{\mathrm{ab}}$ & $319.5 \pm 6.3$ & $342.4 \pm 12.0$ & $1.07 \pm 0.03^{\mathrm{a}}$ \\
\hline \multirow[t]{4}{*}{40} & 0.00 & $5.0 \pm 0.3^{\mathrm{ab}}$ & $324.9 \pm 4.7$ & $346.6 \pm 5.8$ & $1.06 \pm 0.02^{\mathrm{a}}$ \\
\hline & 0.13 & $4.9 \pm 0.4^{\mathrm{b}}$ & $322.5 \pm 10.6$ & $338.5 \pm 12.3$ & $1.04 \pm 0.01^{\mathrm{ab}}$ \\
\hline & 0.25 & $5.2 \pm 0.4^{\mathrm{ab}}$ & $320.4 \pm 5.3$ & $347.8 \pm 7.0$ & $1.08 \pm 0.01^{\mathrm{a}}$ \\
\hline & 0.50 & $4.9 \pm 0.4^{\mathrm{ab}}$ & $321.3 \pm 5.5$ & $337.5 \pm 1.9$ & $1.04 \pm 0.02^{\mathrm{ab}}$ \\
\hline \multicolumn{6}{|c|}{ Statistical significance } \\
\hline \multicolumn{2}{|c|}{ Casein } & $p=0.027$ & & & $p=0.041$ \\
\hline \multicolumn{2}{|c|}{ Leucine } & NS & & & NS \\
\hline \multicolumn{2}{|c|}{ Casein $\times$ Leucine } & $p=0.008$ & & & $p=0.006$ \\
\hline
\end{tabular}

Values are mean \pm SD. $n=3-6$. Data were tested by two-way ANOVA, to analyze the casein and leucine effect. When a significant interaction was detected, Tukey-Kramer tests for multiple comparisons were performed to determine significant differences among individual groups. Labeled values in the same column without a common letter are statistically different, $p<0.05$.

The membranes were reacted with primary antibodies (ASNS: Epitomics Inc., San Francisco, CA; PHGDH: supplied by Furuya S.; SDS: Sigma-Aldrich, St. Louis, MO; $\beta$-actin: Imgenex, San Diego, CA) diluted $1: 1,000$ in blocking buffer overnight at $4^{\circ} \mathrm{C}$ or for $1 \mathrm{~h}$ at room temperature. The blots were washed $3 \times 10$ min with PBS containing $0.1 \%$ Tween 20, and then incubated with secondary antibodies (anti-rabbit horseradish peroxidase: Vector Laboratories Inc., Burlingame, CA) diluted $1: 1,000$ in blocking buffer for $1 \mathrm{~h}$ at room temperature. The blot was washed $3 \times 10$ min with PBS containing $0.1 \%$ Tween 20 , and then chemiluminescence was detected with an image analyzer (LAS-1000, Fuji Film, Tokyo, Japan).

Statistical analysis. Data were expressed as mean \pm SD. Data were tested by two-way ANOVA, to analyze the casein and leucine effect (27). Tukey-Kramer tests for multiple comparisons were performed to determine the significance of differences (27). A difference was considered significant at $p<0.05$. The analysis was performed by JMP 5.1.2 for Macintosh computers (SAS Institute Inc., Cary, NC).

\section{RESULTS}

Effects of leucine administered with diet or by oral supplementation between meals on food intake and growth rate of rats (Experiments 1 and 2)

We examined the effects of varying amounts of leucine given with the diet or orally on the food intake and growth rate of rats maintained on a 6,12 or $40 \%$ casein diet. Two-way ANOVA revealed a significant effect of leucine on the food intake and growth rate of rats when it was included in the diet (Table 2), but not when given orally (Table 3). However, there was a significant interaction between casein and leucine in both the administration methods; thus, we performed multiple comparisons to determine the significance of the differences (Tables 2 and 3). The results showed that leucine supplementation in the diet significantly decreased the food intake and growth rate in a dose-dependent manner in the $6 \%$ casein groups, but not in the 12 or $40 \%$ casein groups (Table 2). Namely, the food intake of the rats fed a diet containing $8 \%$ leucine decreased to $46 \%$ compared with that of the rats fed a $6 \%$ casein diet without leucine addition. Similarly, the growth rate decreased to $0.89 \pm 0.04$ when given a diet containing $8 \%$ leucine (Table 2). However, in contrast to the diet containing leucine, there were no significant differences within the 6, 12 and 40\% casein diet groups when leucine was supplemented orally (Table 3).

Leucine either administered with diet or orally between meals similarly affected the expression of Asns, Phgdh and Sds (Experiments 1 and 2)

Gene expression measured by quantitative realtime PCR was analyzed by the two-way ANOVA. The result indicated that both casein and leucine affected the expression of Asns, Phgdh and Sds mRNA. Leucine administered either with the diet or orally between meals decreased the high expression of Asns and Phgdh that was induced by the $6 \%$ casein diet in a dose-dependent manner. On the other hand, the $S d s$ expression was induced by the $40 \%$ casein diet, and leucine increased the $S d s$ mRNA expression in a dose-dependent manner (Fig. 1a, b). We confirmed by using Western blot analy- 
a
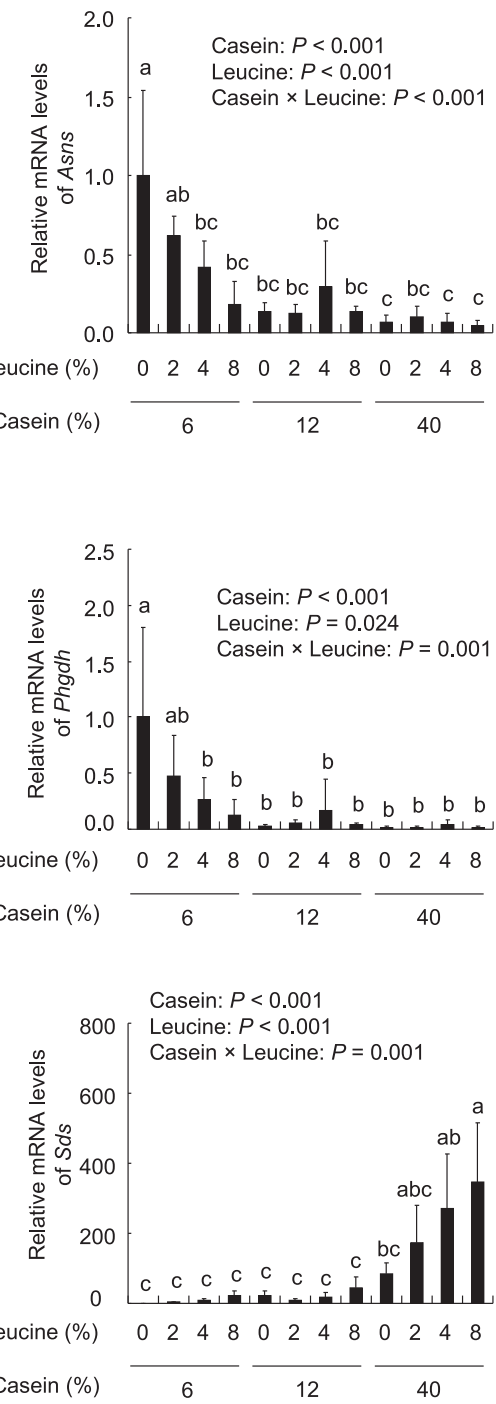

b
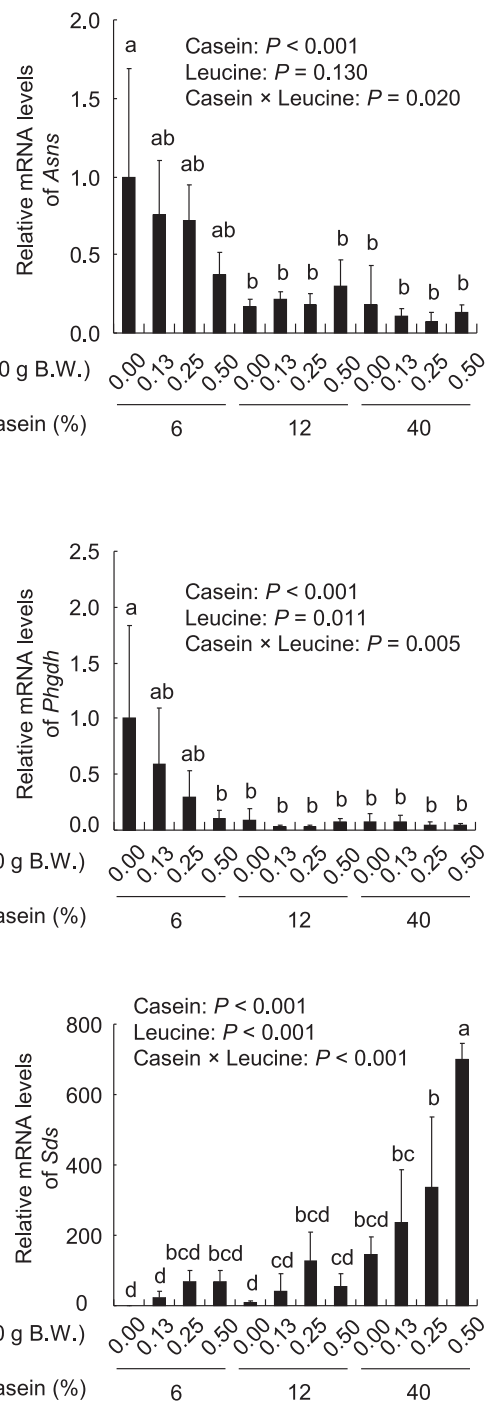

Fig. 1. Effects of diet and oral administration of leucine on Asns, Phgdh and Sds mRNA expression in the rat liver. (a) Rats were fed a 6,12 or $40 \%$ casein diet containing $0,2,4$ or $8 \%$ leucine for 1 wk. (b) Rats fed a 6,12 or $40 \%$ casein diet were subjected to oral administration of leucine at $0,0.13,0.25$ or $0.50 \mathrm{~g} / 100 \mathrm{~g}$ body weight for $1 \mathrm{wk}$. Data were tested by two-way ANOVA, to analyze the casein and leucine effect. Results are shown in figures, respectively. When a significant interaction was detected, Tukey-Kramer tests for multiple comparisons were performed to determine the significance of the differences among individual groups. Values are mean \pm SD. $n=3-6$. Labeled values without a common letter are statistically different, $p<0.05$.

Table 4. Food intake and growth rate of rats fed with branched-chain amino acids.

\begin{tabular}{lcccc}
\hline & & \multicolumn{2}{c}{ Body weight } & \\
\cline { 3 - 4 } Group & $\begin{array}{c}\text { Food intake } \\
(\mathrm{g} / 100 \mathrm{~g} \text { B.W./d) }\end{array}$ & $\begin{array}{c}\text { Beginning } \\
(\mathrm{g})\end{array}$ & $\begin{array}{c}\text { Growth rate } \\
\text { (Fold) } \\
(\mathrm{g})\end{array}$ & \\
\hline Control & $6.4 \pm 0.4^{\mathrm{a}}$ & $355.2 \pm 11.5$ & $406.1 \pm 21.3$ & $1.13 \pm 0.03^{\mathrm{a}}$ \\
Leucine & $3.3 \pm 0.7^{\mathrm{c}}$ & $351.5 \pm 5.8$ & $315.3 \pm 17.5$ & $0.89 \pm 0.05^{\mathrm{c}}$ \\
Isoleucine & $5.2 \pm 0.2^{\mathrm{b}}$ & $358.0 \pm 7.7$ & $379.3 \pm 5.4$ & $1.06 \pm 0.02^{\mathrm{b}}$ \\
Valine & $5.2 \pm 0.2^{\mathrm{b}}$ & $350.0 \pm 8.7$ & $372.3 \pm 10.9$ & $1.06 \pm 0.02^{\mathrm{b}}$ \\
\hline
\end{tabular}

Values are mean \pm SD. $n=5$. Data were tested using Tukey-Kramer tests. Labeled values in the same column without a common letter are statistically different, $p<0.05$. 
sis that the protein level of these enzymes changed concomitantly with the changes in mRNA expressions (data not shown).

Specific effects of leucine among the BCAAs on Asns, Phgdh and Sds gene expression (Experiment 3)

We fed rats with a leucine, isoleucine or valine diet, containing the same amount of nitrogen. The effect of isoleucine and valine was marginal compared with that of leucine on the food intake and growth rate of rats (Table 4). Leucine suppressed the food intake to $50 \%$ compared with that in the control, and decreased the growth rate to $0.89 \pm 0.05$. However, isoleucine and valine suppressed the food intake to $80 \%$ compared with that in the control, and the growth rate was $1.06 \pm 0.02$. The data indicated that among the BCAAs, excess leucine intake strongly suppressed food intake and weight gain. Moreover, compared with leucine, isoleucine and valine had weaker effects on the expression of Asns and Phgdh mRNA, and they did not induce Sds mRNA expression (Fig. 2a). These changes in the mRNA levels were accompanied by similar changes in protein levels (Fig. 2b).

\section{DISCUSSION}

The food intake and growth rate decreased with excess leucine intake in the $6 \%$ casein diet group, but not in the 12 or $40 \%$ casein diet groups (Table 2 ). In contrast, oral administration of leucine did not significantly change the food intake or growth rate (Table 3), indicating that the effects of leucine depend on the timing of administration. On the other hand, both dietary intake and oral administration of leucine decreased Asns and Phgdh mRNA expression in the $6 \%$ casein diet and increased Sds mRNA expression in the $40 \%$ casein diet in a dosedependent manner (Fig. 1a, b). The effect of leucine on gene expression appears to be specific, because isoleucine and valine did not change the expression of ASNS, PHGDH or SDS (Fig. 2). Although the expression of ASNS and PHGDH in rat liver is known to be induced by a low-protein diet $(11,12)$, we revealed here for the first time that leucine downregulates the expression of ASNS and PHGDH in vivo.

We hypothesized that changes in ASNS, PHGDH and SDS expression contribute to growth retardation in rats during excess leucine intake. Decreased expression of ASNS and PHGDH, amino acid synthesis enzymes, and increased expression of SDS, an amino acid catabolic enzyme, may cause an amino acid imbalance. Interestingly, although dietary leucine intake caused growth retardation while oral administration did not, the gene expression patterns of Asns, Phgdh and Sds were similar in both cases. This suggests that there are no causal relationships between ASNS, PHGDH and SDS expression and growth retardation.

In rats showing growth retardation, the food intake was markedly reduced. We have previously found that vagotomy recovered the reduced food intake caused by dietary leucine (28). On the other hand, Cota et al. have reported that intraventricular administration of leucine suppressed food intake through the hypothalamic mam- a
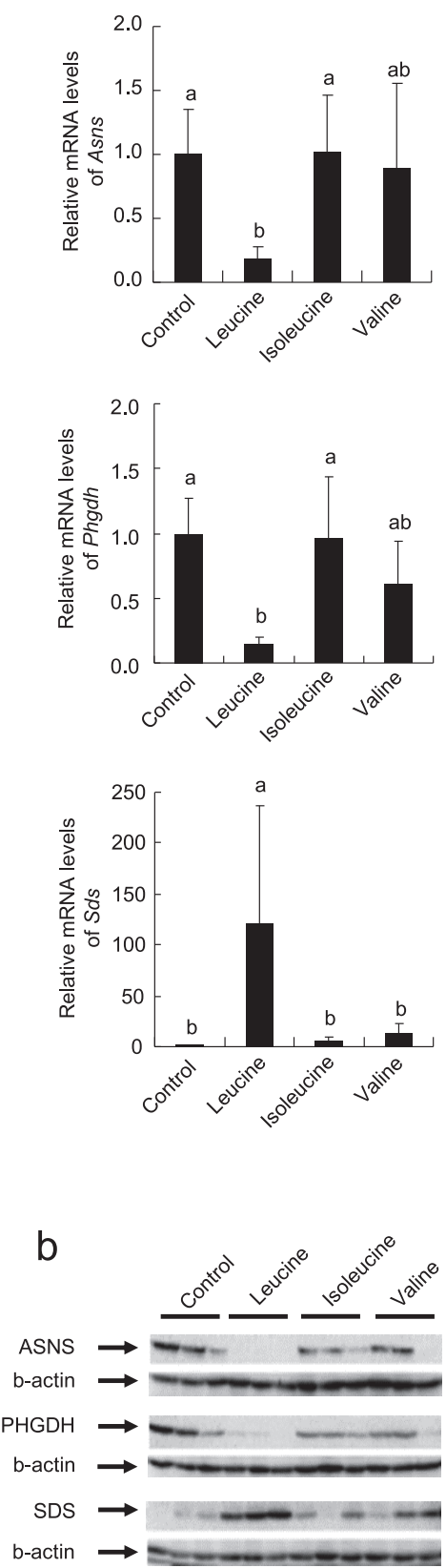

Fig. 2. The effects of BCAA on ASNS, PHGDH and SDS expression in rat liver. (a) Asns, Phgdh and Sds mRNA expression in the liver of rats fed with a leucine, isoleucine or valine diet, containing the same amount of nitrogen. (b) The abundance of ASNS, PHGDH and SDS protein in the rat liver. Tukey-Kramer tests for multiple comparisons were performed to determine the significance of the differences among individual groups. Values are mean \pm SD. $n=5$. Labeled values without a common letter are statistically different, $p<0.05$.

malian target of rapamycin (mTOR) activation (29). Thus, leucine may suppress food intake via the vagal nerve and/or by activation of the hypothalamic mTOR pathway. From this point of view, growth retardation is primarily mediated through the suppression of food intake. In contrast to dietary leucine, the orally administered leucine did not cause suppression of food intake, 
which could be because of the time of leucine intake. When rats were given leucine orally between meals, the effect of leucine was attenuated, and by the next feeding the rats ate a normal amount. Indeed, plasma leucine transiently increased at $30 \mathrm{~min}$ and returned to the basal level $2 \mathrm{~h}$ after oral administration of BCAA enrichment (30). On the other hand, we did not observe the decreased food intake caused by an excess amount of leucine when the rats were fed a $12 \%$ or $40 \%$ casein diet. Niijima et al. have reported that the sensitivity of L-lysine sensors in the hepato-portal region was 100fold higher in L-lysine-deficient rats than in normal rats (31). Thus, sensitivity of the amino acids sensors may therefore have increased in the rats maintained on a $6 \%$ casein diet.

It has been demonstrated that de novo synthesis of asparagine and serine was critical for cellular growth and function $(16,18-21)$. ASNS and PHGDH are known to be expressed in several tissues at different levels. This suggests that the expression of these enzymes depends on the metabolic demand of the tissues for asparagine and serine. If leucine changes the expression of ASNS and PHGDH in respective tissues, it may affect their physiological function in the tissues. For example, an adverse effect of leucine on the immune system has been reported (32). Thus, to further understand the effects of the leucine-induced amino acid imbalance, it should be determined whether leucine affects the expression of ASNS and PHGDH in tissues other than the liver in relation to the tissue function.

Because the liver is a dominant organ for amino acid homeostasis, induction of ASNS and PHGDH seems to be an adaptation to amino acid deficiency, to provide adequate asparagine and serine to peripheral tissues to fulfill their metabolic demand for maintaining cellular functions under low-protein nutrition. The amino acid response (AAR) pathway, a signal transduction pathway activated to sense amino acid deficiency, was found during the study of the induction mechanism of ASNS in a cultured cell line. The AAR pathway is activated by a deficiency in amino acids, particularly indispensable amino acids, and the translation of the downstream activating transcription factor 4 (ATF4) is stimulated $(33,34)$. ATF4 binds to a specific element called nutrient-sensing response element-1 (NSRE1), which exists within the Asns promoter, and activates Asns transcription. The AAR pathway is suppressed by addition of a single indispensable amino acid including leucine to the culture medium. We demonstrated here that the expression of ASNS was increased by feeding rats a low-protein diet, and the induction was suppressed by administration of leucine, suggesting that the AAR pathway is involved in the adaptive change in ASNS in response to protein nutrition in vivo. It is conceivable that the concomitant expression of PHGDH and ASNS is regulated through the AAR pathway. However, we could not find a putative NSRE1 in the promoter region of Phgdh with a data base search (data not shown). On the other hand, it has been reported that PHGDH expression in rat liver is induced by insulin and suppressed by glucocorticoid
$(11,35)$, though there were no reports of hormonal regulation of ASNS. Recently, three signal transduction pathways, mTOR, 5' AMP-activated protein kinase (AMPK) and general control nonderepressible 2 (GCN2) have been proposed to be involved in amino acid sensing in the liver, and to coordinately regulate the hepatic energy metabolic pathway in response to protein intake (27). Although we did not examine the regulatory mechanisms of the expression of ASNS, PHGDH and SDS in current study, it seemed that these enzymes were coordinately expressed in response to protein nutrition. Clarifying the regulatory mechanism of these enzymes' expression may provide useful information for understanding the amino acid-sensing mechanism in the liver and the adaptive changes in the hepatic amino acid metabolism in response to protein nutrition.

\section{Acknowledgments}

Part of this work was supported by the International Council on Amino Acid Science (ICAAS) and by grant-aided Scientific Research C (no. 22580140 and 26450157 to R.K.) from the Japan Society for the Promotion of Science. We gratefully acknowledge Dr. Shigeki Furuya (Kyushu University) for providing the antibody for PHGDH. We would also like to thank SanEi Gen F.F.I., Inc. for providing xanthane gum.

\section{REFERENCES}

1) Anthony JC, Reiter AK, Anthony TG, Crozier SJ, Lang CH, MacLean DA, Kimball SR, Jefferson LS. 2002. Orally administered leucine enhances protein synthesis in skeletal muscle of diabetic rats in the absence of increases in 4E-BP1 or S6K1 phosphorylation. Diabetes 51: 928-936.

2) Anthony JC, Yoshizawa F, Anthony TG, Vary TC, Jefferson LS, Kimball SR. 2000. Leucine stimulates translation initiation in skeletal muscle of postabsorptive rats via a rapamycin-sensitive pathway. J Nutr 130: 2413-2419.

3) Kadowaki M, Kanazawa T. 2003. Amino acids as regulators of proteolysis. J Nutr 133: 2052s-2056s.

4) Yamamoto D, Maki T, Herningtyas EH, Ikeshita N, Shibahara H, Sugiyama Y, Nakanishi S, Iida K, Iguchi G, Takahashi Y, Kaji H, Chihara K, Okimura Y. 2010. Branched-chain amino acids protect against dexamethasone-induced soleus muscle atrophy in rats. Muscle Nerve 41: 819-827.

5) Harper AE, Miller RH, Block KP. 1984. Branched-chain amino acid metabolism. Annu Rev Nutr 4: 409-454.

6) Harper AE, Monson WJ, Benton DA, Winje ME, Elvehjem CA. 1954. Factors other than choline which affect the deposition of liver fat. J Biol Chem 206: 151-158.

7) Rogers QR, Tannous RI, Harper AE. 1967. Effects of excess leucine on growth and food selection. J Nutr 91: 561-572.

8) Kumta US, Elias LG, Harper AE. 1961. Amino acid balance and imbalance: VI. Growth depressions from additions of amino acids to diets low in fibrin. J Nutr 73: 229-235.

9) Henderson LM, Koeppe OJ, Zimmerman HH. 1953. Niacin-tryptophan deficiency resulting from amino acid imbalance in non-casein diets. J Biol Chem 201: 697-706.

10) Imamura W, Yoshimura R, Takai M, Yamamura J, Kana- 
moto R, Kato H. 2013. Adverse effects of excessive leucine intake depend on dietary protein intake: a transcriptomic analysis to identify useful biomarkers. J Nutr Sci Vitaminol 59: 45-55.

11) Hayashi S, Tanaka T, Naito J, Suda M. 1975. Dietary and hormonal regulation of serine synthesis in the rat. J Biochem 77: 207-219.

12) Hongo S, Matsumoto T, Suzuki I, Sato T. 1979. Effect of dietary protein content on the activity of rat liver asparagine synthetase. J Biochem 86: 385-390.

13) Arfin SM, Cirullo RE, Arredondo-Vega FX, Smith M. 1983. Assignment of structural gene for asparagine synthetase to human chromosome 7. Somatic Cell Genet 9: $517-531$.

14) Balasubramanian MN, Butterworth EA, Kilberg MS. 2013. Asparagine synthetase: regulation by cell stress and involvement in tumor biology. Am J Physiol Endocrinol Metab 304: E789-E799.

15) Rogers QR, Chen DM, Harper AE. 1970. The importance of dispensable amino acids for maximal growth in the rat. Proc Soc Exp Biol Med 134: 517-522.

16) Story MD, Voehringer DW, Stephens LC, Meyn RE. 1993. L-asparaginase kills lymphoma cells by apoptosis. Cancer Chemother Pharmacol 32: 129-133.

17) Richards NG, Kilberg MS. 2006. Asparagine synthetase chemotherapy. Annu Rev Biochem 75: 629-654.

18) Yoshida K, Furuya S, Osuka S, Mitoma J, Shinoda Y, Watanabe M, Azuma N, Tanaka H, Hashikawa T, Itohara S, Hirabayashi Y. 2004. Targeted disruption of the mouse 3-phosphoglycerate dehydrogenase gene causes severe neurodevelopmental defects and results in embryonic lethality. J Biol Chem 279: 3573-3577.

19) Yang JH, Wada A, Yoshida K, Miyoshi Y, Sayano T, Esaki K, Kinoshita MO, Tomonaga S, Azuma N, Watanabe M, Hamase K, Zaitsu K, Machida T, Messing A, Itohara S, Hirabayashi Y, Furuya S. 2010. Brain-specific Phgdh deletion reveals a pivotal role for L-serine biosynthesis in controlling the level of D-serine, an N-methyl-D-aspartate receptor co-agonist, in adult brain. J Biol Chem $\mathbf{2 8 5}$ : 41380-41390.

20) Locasale JW, Grassian AR, Melman T, Lyssiotis CA, Mattaini KR, Bass AJ, Heffron G, Metallo CM, Muranen T, Sharfi H, Sasaki AT, Anastasiou D, Mullarky E, Vokes NI, Sasaki M, Beroukhim R, Stephanopoulos G, Ligon AH, Meyerson M, Richardson AL, Chin L, Wagner G, Asara JM, Brugge JS, Cantley LC, Vander Heiden MG. 2011. Phosphoglycerate dehydrogenase diverts glycolytic flux and contributes to oncogenesis. Nat Genet 43: 869-874.

21) Possemato R, Marks KM, Shaul YD, Pacold ME, Kim D, Birsoy K, Sethumadhavan S, Woo HK, Jang HG, Jha AK, Chen WW, Barrett FG, Stransky N, Tsun ZY, Cowley GS, Barretina J, Kalaany NY, Hsu PP, Ottina K, Chan AM, Yuan B, Garraway LA, Root DE, Mino-Kenudson M, Brachtel EF, Driggers EM, Sabatini DM. 2011. Functional genomics reveal that the serine synthesis pathway is essential in breast cancer. Nature 476: 346-350.

22) Xue HH, Fujie M, Sakaguchi T, Oda T, Ogawa H, Kneer NM, Lardy HA, Ichiyama A. 1999. Flux of the L-serine metabolism in rat liver. The predominant contribution of serine dehydratase. J Biol Chem 274: 16020-16027.

23) Imai S, Kanamoto R, Yagi I, Kotaru M, Saeki T, Iwami K. 2003. Response of the induction of rat liver serine dehydratase to changes in the dietary protein requirement. Biosci Biotechnol Biochem 67: 383-387.

24) Kanamoto R, Fujita K, Kumasaki M, Imai S, Kotaru M, Saeki T, Iwami K. 2004. Inverse correlation between the nitrogen balance and induction of rat liver serine dehydratase (SDH) by dietary protein. Biosci Biotechnol Biochem 68: 888-893.

25) Zhong B, Sakai S, Saeki T, Kanamoto R. 2007. Excess leucine intake induces serine dehydratase in rat liver. Biosci Biotechnol Biochem 71: 2614-2617.

26) Chomczynski P, Sacchi N. 1987. Single-step method of RNA isolation by acid guanidinium thiocyanate-phenolchloroform extraction. Anal Biochem 162: 156-159.

27) Chotechuang N, Azzout-Marniche D, Bos C, Chaumontet C, Gausseres N, Steiler T, Gaudichon C, Tome D. 2009. mTOR, AMPK, and GCN2 coordinate the adaptation of hepatic energy metabolic pathways in response to protein intake in the rat. Am J Physiol Endocrinol Metab 297: E1313-E1323.

28) Yoshimura R, Ho YY, Mizushige T, Ohinata K, Kanamoto R. 2013. The vagotomy alleviates the anorectic effect of an excess amount of dietary leucine on rats fed a lowprotein diet. Biosci Biotechnol Biochem 77: 1593-1594.

29) Cota D, Proulx K, Smith KA, Kozma SC, Thomas G, Woods SC, Seeley RJ. 2006. Hypothalamic mTOR signaling regulates food intake. Science 312: 927-930.

30) D'Antona G, Ragni M, Cardile A, Tedesco L, Dossena M, Bruttini F, Caliaro F, Corsetti G, Bottinelli R, Carruba MO, Valerio A, Nisoli E. 2010. Branched-chain amino acid supplementation promotes survival and supports cardiac and skeletal muscle mitochondrial biogenesis in middle-aged mice. Cell Metab 12: 362-372.

31) Niijima A, Torii K, Uneyama H. 2005. Role played by vagal chemical sensors in the hepato-portal region and duodeno-intestinal canal: an electrophysiological study. Chem Senses 30(Suppl 1): i178-i179.

32) Gatnau R, Zimmerman DR, Nissen SL, Wannemuehler M, Ewan RC. 1995. Effects of excess dietary leucine and leucine catabolites on growth and immune responses in weanling pigs. J Anim Sci 73: 159-165.

33) Chaveroux C, Lambert-Langlais S, Cherasse Y, Averous J, Parry L, Carraro V, Jousse C, Maurin AC, Bruhat A, Fafournoux P. 2010. Molecular mechanisms involved in the adaptation to amino acid limitation in mammals. Biochimie 92: 736-745.

34) Palii SS, Kays CE, Deval C, Bruhat A, Fafournoux P, Kilberg MS. 2009. Specificity of amino acid regulated gene expression: analysis of genes subjected to either complete or single amino acid deprivation. Amino Acids 37: 79-88.

35) Achouri Y, Robbi M, Van Schaftingen E. 1999. Role of cysteine in the dietary control of the expression of 3-phosphoglycerate dehydrogenase in rat liver. Biochem J 344(Pt 1): 15-21. 